\title{
Quantitative determination of HER2 expression by confocal microscopy assay in CTCs of breast cancer
}

\author{
SHENG CAO ${ }^{1,5^{*}}$, YANG LI ${ }^{2,5^{*}}, \mathrm{JIN} \mathrm{LI}^{3,4^{*}}$, CHANG-FEI LI ${ }^{5}$, \\ WEI ZHANG ${ }^{6}$, ZENG-QI YANG ${ }^{1}$ and SONG-DONG MENG ${ }^{5}$
}

\begin{abstract}
${ }^{1}$ College of Veterinary Medicine, Northwest A and F University, Yangling, Shaanxi 712100; ${ }^{2}$ College of Life Science, Sichuan Normal University, Chengdu 610066; ${ }^{3}$ Department of Microbiology, Peking University Health Science Center, Beijing 100191; ${ }^{4}$ Beijing Tiantan Biological products Co., Ltd, Beijing 100024; ${ }^{5}$ CAS Key Laboratory of Pathogenic Microbiology and Immunology, Institute of Microbiology, Chinese Academy of Sciences (CAS), Beijing 100101;

${ }^{6}$ Cancer Institute and Hospital, Chinese Academy of Medical Sciences, Beijing 100021, P.R. China
\end{abstract}

Received August 4, 2009; Accepted October 19, 2009

DOI: 10.3892/or_00000651

\begin{abstract}
HER2 analysis in circulating tumor cells (CTCs) may have clinical significance for HER2-targeted therapy as HER2-positive CTCs and disseminated tumor cells can be detected in patients with HER2-negative primary tumors who currently do not have access to HER2-targeted therapy. In this study, we performed quantitative analysis by confocal microscopy assay for evaluation of HER2 expression in individual tumor cells. HER 2 testing by confocal microscopy assay exhibited high concordance with results of real-time PCR, Western blot analysis and FISH analysis. We found that there was a significant positive correlation between HER2 overexpression and gene amplification in individual CTCs, which provided validation of confocal microscopy assay for HER2 expression in CTCs. By using subsets of 10 consecutive cells (bins), we conclude that HER2 expression (3+) in CTCs predicts HER 2 overexpression of tumor with high probability in breast cancer patients. These results may provide interpretive guidelines for HER2 status assay in CTCs and raise great opportunities for using CTCs as non-invasive and 'real-time' biopsy to examine and monitor the status of tumor markers.
\end{abstract}

Correspondence to: Dr Song-dong Meng, Institute of Microbiology, Chinese Academy of Sciences, 1-3 West Beichen Road, Beijing 100101, P.R. China

E-mail: mengsd@im.ac.cn

${ }^{*}$ Contributed equally

Abbreviations: CTCs, circulating tumor cells; DTC, disseminated tumor cells; IF, immunofluorescence; ER, oestrogen receptor; FISH, fluorescence in situ hybridization

Key words: HER2, overexpression, confocal microscopy assay, circulating tumor cells, quantitative measurement

\section{Introduction}

There is growing literature on biological and clinical significance of circulating tumor cells (CTCs) in the peripheral blood and disseminated tumor cells (DTCs) in the bone marrow in cancer patients (1-3). Distant metastases through the blood and lymphatic system are the main cause of cancer-related death. The presence of CTCs or DTCs in patients with both localized and metastatic cancer is known to be associated with a higher risk of recurrence and worse prognosis (4-6). Moreover, CTCs can be detected in breast cancer patients many years after mastectomy without evidence of disease, a phenomenon called 'cancer dormancy' (7).

It is well documented that there are extensive genetic changes and clonal heterogeneity in cancer lesions. However, at present there is no simple and efficient method to follow the genetic changes in the heterogeneous tumors or to utilize cutting edge molecular technologies to further characterize the tumor as cancer progresses. Repeated invasive biopsies are unacceptable. There is considerable evidence that CTCs/DTCs $(2,3,8-10)$ are an effective means for following genetic changes that accompany cancer progression. Our previous studies $(11,12)$ showed that protein expression levels and gene amplification of HER 2 could change throughout disease progression and HER2 and UPAR overexpression and gene amplification are correlated by analysis of gene status and expression in CTCs. In these studies we subjectively quantified gene expression levels of individual CTCs into 1-3 categories after immunofluorescence (IF) staining. In other studies IF staining or/and immunohistochemistry $(8,10,13)$ was used for evaluating positivity for HER2, oestrogen-receptor (ER) or other tumor markers. HER2 testing in CTCs may have clinical relevance for HER2-targeted therapy as HER2-positive CTCs and DTCs can be detected in patients with HER2-negative primary tumors who currently do not have access to HER2targeted therapy (e.g. the humanized monoclonal antibody targeting HER2, trastuzumab) $(2,8,14)$. These data are consistent with our previous observation that HER2 expression levels in CTCs may change as breast cancer progresses (11). 
Although several studies have been done on quantitative measurements of HER2 expression in tumor tissue by immunofluorescence-based assay $(15,16)$, real-time PCR (17) or microarray (18), few have investigated in individual CTCs/DTCs. The aim of this study was to set up a quantitative analysis method for evaluation of HER2 expression in individual tumor cells (e.g. CTCs/DTCs) by confocal microscopy assay. We assessed the accuracy and reliability of this approach in breast cancer cell lines and individual CTCs from breast cancer patients and compared its accuracy to FISH (fluorescence in situ hybridization) as the criterion standard.

\section{Materials and methods}

Cell lines and culture conditions. Four breast cancer cell lines (SKBR3, ZR 751, MDA MB 231, MCF-7) and one prostate cancer cell line (PC3) were obtained from ATCC (America Rockville, MD). The cultures were incubated at $37^{\circ} \mathrm{C}$ in a humidified atmosphere of $5 \% \mathrm{CO}_{2}$.

Knock down of HER2 gene expression levels by siRNA. We designed shRNA duplexes targeting human HER2 gene according to a published study (19) and shRNA duplexes targeting EGFP gene was designed as control. All the constructed plasmids were confirmed by DNA sequencing. Transfections were performed using Lipofectamine 2000 reagent (Invitrogen) according to manufacturer's instructions.

Real-time PCR. The levels of HER2 mRNA were determined by real-time fluorescence quantitative PCR, using an Applied Biosystems SYBR ${ }^{\circledR}$-Green master mix reagent (Finnzymes, Finland). All reactions were performed in triplicate.

Western blot assay. To detect HER2 expression in breast cancer cells, the total protein was extracted and analyzed with Western blot analysis. Briefly, equal amounts of protein (25 $\mu \mathrm{g}$ /lane) from cell lysates were immunoblotted with antibodies against HER2 (Cell signaling Biotech Inc) and actin (Santa Cruz Biotech Inc), respectively. Actin served as the control.

Isolation of CTCs from breast cancer patients. Thirty patients with primary breast cancer of stage II or III were enrolled in this study, age range 30-46 years. All patients were hospitalized in Cancer Institute and Hospital, Chinese Academy of Medical Sciences from January 2008 and August 2008. IHC for HER2 expression and FISH analysis for HER2 gene amplification in patients were performed by the pathology laboratory on primary tumors to determine their HER2 status. Thirty milliliters of blood was drawn before surgery from each patient in $10 \mathrm{ml}$ Vacutainer tubes (BD Biosciences) containing EDTA and processed within $4 \mathrm{~h}$ of collection. None of the patients received any treatment within a month prior to the blood test. All blood samples were obtained with informed consent and collected by using protocols approved by the Institutional Review Board at Chinese Academy of Medical Sciences. Enrichment and isolation of CTCs from blood were performed as described (11). Slides were stored at $-20^{\circ} \mathrm{C}$.
IF for quantitative analysis by confocal microscopy. IF staining was carried out as described (11). Anti-HER2 antibody conjugated to Alexa Fluor 594 (Molecular Probes) was used for IF staining in cell lines and CTCs and mouse isotope $\operatorname{IgG}$ was used as control. Monoclonal mouse antipan-cytokeratin clone C11-FITC (Sigma) and monoclonal mouse anti-CD45 (clone 9.4 from ATCC) conjugated to Alexa Fluor 546 were used for IF staining in CTCs. A Leica SP2 confocal microscope was used for collecting fluorescence images. Bright field (BF), Alexa Fluor 594 (excitation $594 \mathrm{~nm}$, emission 590-617 nm) and Alexa Fluor 546 (excitation $546 \mathrm{~nm}$, emission 556-573 nm) fluorescence were captured using sequential acquisition to give separate image files for each field (1024x1024 pixels, 8-bit). Pinhole diameter, scan speed and laser powers were optimized. Photomultiplier tube gain and offset were adjusted to give sub-saturating fluorescence intensity with optimal signal to noise ratio. Image analysis was performed using Image Jv3.91 software. As IF with anti-HER2 antibody stains periphery of cells, to define a binary image mask, these areas were chosen by using polygon selections function of the Image Jv3.91 software in BF, which serves as the 'Region of Interest' (ROI). Then the ROI was applied to equipotential fluorescence image (Alexa Fluor 594) and integrated density of HER2 staining was measured. SKBR3 served as positive control, variation $<10 \%$.

Multicolor FISH. FISH analysis was performed as previously described (12).

Statistical analysis. Exact binomial t-test or Mann-Whitney non-parametric $U$ test were used for comparison between groups. Spearman correlation analysis was performed between HER2 expression and gene amplification. Value of $\mathrm{P}<0.05$ was considered as a statistically significant difference.

\section{Results}

Setting cutoff scores for classification of HER2 expression levels. We first chose 4 breast cancer cell lines (SKBR3, ZR 751, MDA MB 231, MCF-7) and one prostate cancer cell line (PC3) with different HER2 expression levels to set cutoff scores for the 3 categories used in our previous studies $(7,11)$. These 5 cell lines were stained with IF for HER2 expression. HER2 expression levels were either scored subjectively into 1-3 categories, or quantified by confocal microscopy as shown in Fig. 1. Using Image Jv3.91 software to analyze the fluorescence intensity distribution, the mean gray value and standard deviation (SD) values were obtained. One hundred cells for each cell line were tested for HER2 expression by confocal microscopy and subjective scoring. As shown in Table I, the mean gray values are significantly different among cell lines with categories of $1+, 2+$ or $3+$, category 1 (PC3): 9.66 (SD 2.25); category 2 (MDA MB 231 and MCF-7 cells): 20.78 (SD 6.02); category 3 (SKBR3 and ZR 751 cells): 80.42 (SD26.13). The cutoff scores were set according to Mean Gray Value $\pm 2 x S D$. Then, the cutoff scores were defined as 5.16 to 14.16 for category $1+, 8.74$ to 32.82 for category $2+$ and 28.16 to 132.68 for category $3+$. To avoid overlap in scores between categories, the cutoff score was 

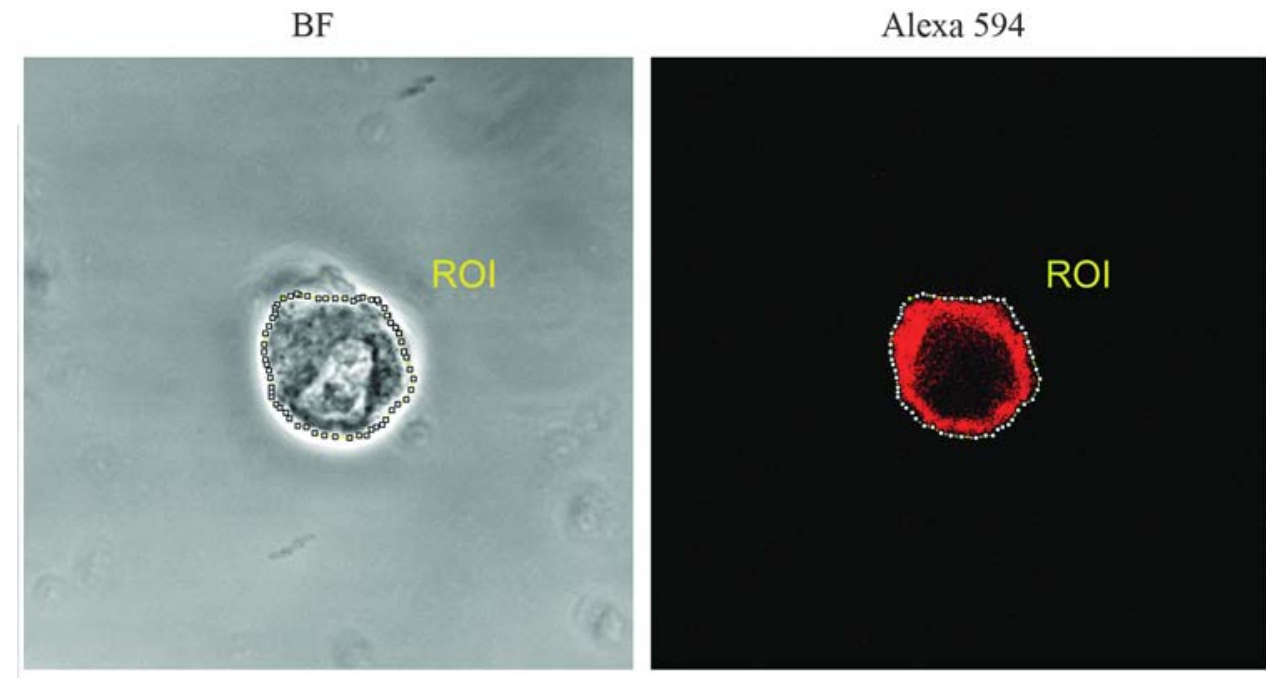

\author{
Max Gray Value: 255 \\ Min Gray Value: 0 \\ Standard Deviation: 40.730 \\ Mean Gray Value: 82.775 \\ Area: 45761 \\ Integrated Density: 3787866 \\ $10 \mu \mathrm{m}$
}

Figure 1. Calculating of HER2 fluorescence staining in SKBR3 cells by confocal microscope. The image for each individual cell with IF staining was analyzed by confocal microscope assay system. Left, the periphery region of cells where IF with anti-HER2 antibody stains were chosen by using polygon selections function of the Image Jv3.91 software in bright field (BF) as the 'Region of Interest' (ROI). Right, the ROI was applied to equipotential fluorescence image, and integrated density of HER2 staining was measured. Mean gray value and standard deviation values for each cell were obtained as shown on the right.

Table I. Setting cutoff scores for confocal microscopy assay.

\begin{tabular}{lccc}
\hline IFI & $1+$ & $2+$ & $3+$ \\
\hline Mean gray value $^{\mathrm{a}}$ & 9.66 & 20.78 & 80.42 \\
Standard deviation (SD) $^{2}$ & 2.25 & 6.02 & 26.13 \\
Cutoff scores $^{\mathrm{b}}$ & $5.16-14.16$ & $8.74-32.82$ & $28.16-132.68$ \\
Adjusted scores & $5-11$ & $11-30$ & $>30$ \\
\hline
\end{tabular}

${ }^{\mathrm{a}}$ One or two hundred cells were counted in each group and ${ }^{\mathrm{b}}$ the cutoff scores were set as mean gray value $\pm 2 \mathrm{xSD}$. The experiments were repeated twice and similar results were obtained.

adjusted to $<11$ for category 0 or $1+, 11-30$ for category $2+$ and $>30$ for category $3+$.

Validation of confocal microscopy assay in HER2 knocked down cell lines. HER2 siRNA treatment decreased the HER2 mRNA by 81 and $75 \%$, respectively in SKBR3 and ZR 751 cells (Fig. 2A) and HER2 expression was significantly decreased by Western blot analysis (Fig. 2B). Consistent with results of real-time PCR and Western blot analysis, treatment with pHER2 led to decrease of HER2 levels from $3+$ to $2+$ or $0 / 1+$ in $82 \%$ of SKBR3 cells and in $76 \%$ of $\mathrm{ZR}$ 751 cells determined by confocal microscopy (Fig. 2C), indicating that the transfection efficiency ranged from 75 to $85 \%$ in these two cells.

Classification of HER2 levels in individual CTCs by confocal microscopy. Then, we performed confocal microscopy assay in CTCs to assess the technical feasibility and variability. Fig. 3 shows HER2 accurate testing by confocal microscopy in CTCs. The average mean grey values for quantification of HER2 IF staining in cell membrane are illustrated and HER2 expression levels were scored using scoring criterion in
Table I. According to the cutoff scores for classification of HER2 expression levels, HER2 status were expressed as ' $3+$ ', '2+', '0/1+'. Only 3+ was considered as HER2 overexpression. FISH analysis was performed on the same cell after IF staining and HER2/CEP 17 gene ratio is shown in Fig. 3. HER 2 gene amplification is defined as a signal ratio $\geq 2$.

Correlation of HER2 status between CTCs and primary tumors. Thirty breast cancer patients were enrolled in the study and 10 of them had at least 10 CTCs. Conventional analysis for HER2 expression and gene amplification by IHC and FISH was performed by the pathology laboratory in hospital on the 10 primary tumors ( 5 tumors were HER 2 overexpressed and 5 were not). The results of HER2 expression in CTCs by confocal microscopy assay are summarized in Table II. To determine whether the results of HER2 testing in CTCs by confocal microscopy assay were concordant with HER2 status obtained from primary tumor, we used 10 consecutive CTCs (a bin) and HER2 levels of the entire bin were scored by majority of the cells with the same expression. Patients with the majority of bins of $3+$ were considered to be HER2 overexpressed; otherwise as not overexpressed. The results of HER2 status using CTCs compared with the analysis of the pathologist showed concordance in all 10 patients [100\% concordance, with $95 \%$ confidence interval (CI) of 69$100 \%]$.

Exact binomial test was used to compare CTCs with HER2 overexpression $(3+)$ and gene amplification to those with only one of them. We found $\mathrm{P}<0.0001$ in both HER2+ and HER2- patients.

Concordance between Her2 gene amplification by FISH and Her 2 protein expression measured by confocal microscopy in CTCs. In tissue section only HER2 expression $3+$ by IHC is considered to be protein overexpressed and HER gene amplification was found in $>90 \%$ of the breast cancer cases that have HER2 protein overexpression. Spearman correlation analysis were performed to investigate the predictive power 
A
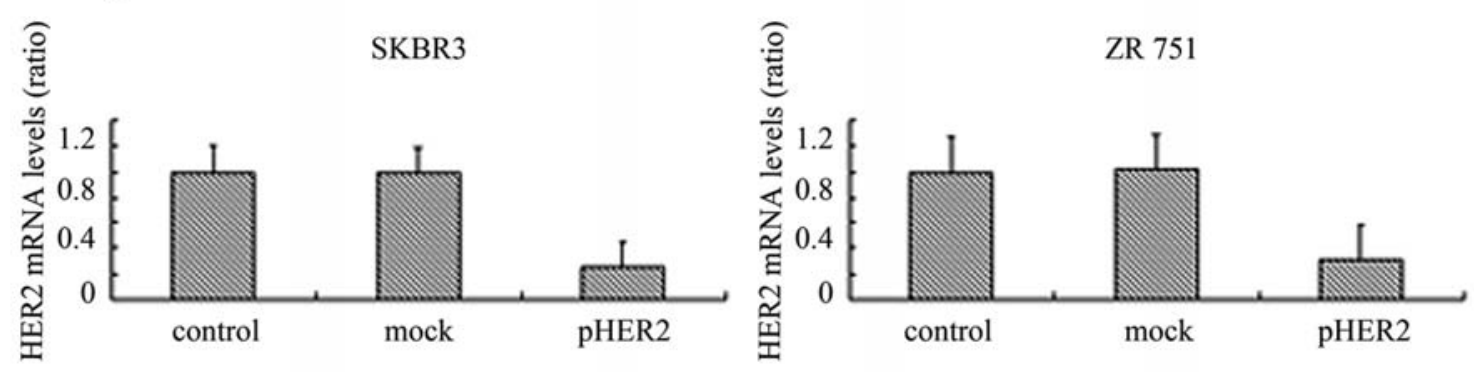

B

SKBR3

control mock pHER2

\begin{tabular}{lll}
\multicolumn{3}{c}{ ZR 751 } \\
\hline control & mock & pHER2
\end{tabular}
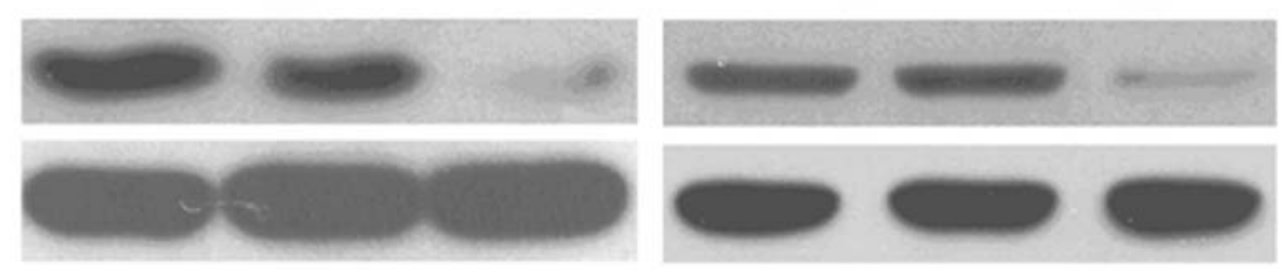

HER2

C
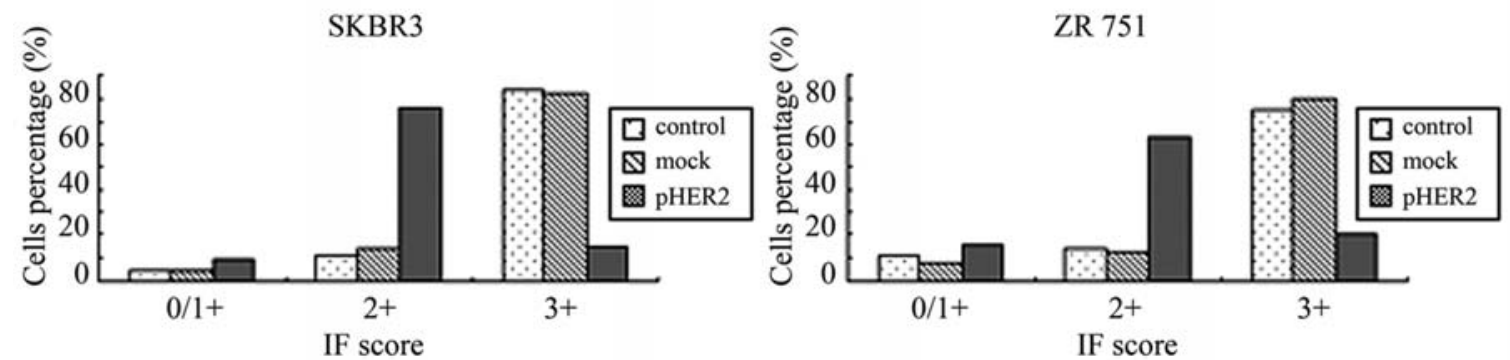

Figure 2. Concordance of HER2 expression levels determined by real-time PCR, Western blot analysis and confocal microscopy. SKBR3 and ZR 751 cells were transfected with reagent control (with no plasmid), GFP siRNA (pGFP) as a mock and HER2 siRNA (pHER2). At the time points of 48 and $72 \mathrm{~h}$ after transfection, HER2 expression was determined respectively by real-time PCR (A) and Western blot analysis (B). Actin served as control. (C) One hundred cells randomly selected in each treatment were analyzed for HER2 IF staining intensity by confocal microscopy. HER2 IF (0-3+) was evaluated according to the cutoff scores in Table I. All the experiments were performed in triplicates and similar results were obtained.

Table II. Concordance of HER2 expression levels between CTCs and primary tumors.

\begin{tabular}{|c|c|c|c|c|c|c|c|c|c|c|}
\hline \multirow[b]{2}{*}{ Patient Number } & \multicolumn{5}{|c|}{ HER2-patients ${ }^{\mathrm{a}}$} & \multicolumn{5}{|c|}{ HER2+ patients ${ }^{\mathrm{a}}$} \\
\hline & $\# 5$ & $\# 12$ & \#19 & $\# 22$ & \#28 & $\# 3$ & \#7 & $\# 17$ & \#23 & $\# 30$ \\
\hline Total number of CTCs & 12 & 20 & 59 & 16 & 42 & 13 & 82 & 46 & 15 & 12 \\
\hline $0 / 1+(\%)^{\mathrm{b}}$ & 100 & 25 & 63 & 19 & 43 & 0 & 12 & 0 & 0 & 0 \\
\hline $2+(\%)^{\mathrm{b}}$ & 0 & 55 & 20 & 62 & 45 & 31 & 31 & 20 & 7 & 17 \\
\hline $3+(\%)^{b}$ & 0 & 20 & 17 & 19 & 12 & 69 & 57 & 80 & 93 & 83 \\
\hline
\end{tabular}

aHER2 status was determined by IHC and FISH analysis in primary rumors. Patients with tumor of IHC $3+$ and FISH amplification were

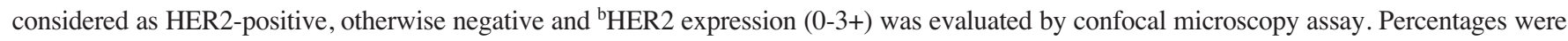
'rounded' for simplicity.

of the level of HER2 expression 3+ in CTCs for gene amplification and gene copy numbers in all patients (Table III). We found that this analysis is highly significant with a P-value of $<0.0001$ for both HER2 gene ratio and copy numbers, whereas no relationship was found for copy numbers of chromosome 17. Thus, in both HER2+ and HER2- patients, there is a marked relationship between HER2 overexpression and gene amplification in individual CTCs. Therefore, HER2 expression 

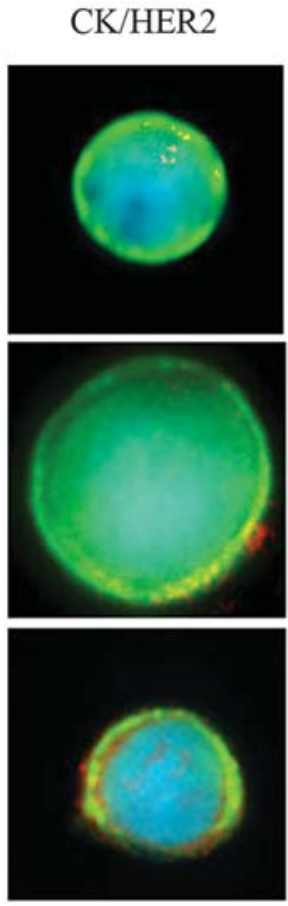
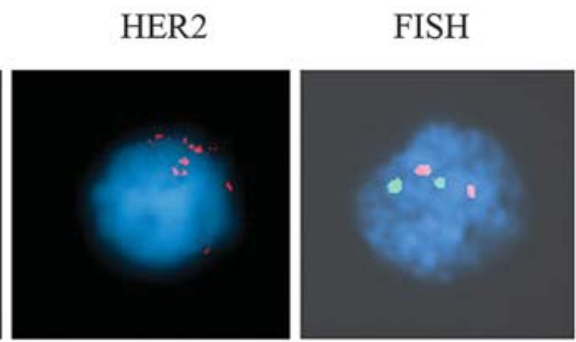

Mean

Gray Value
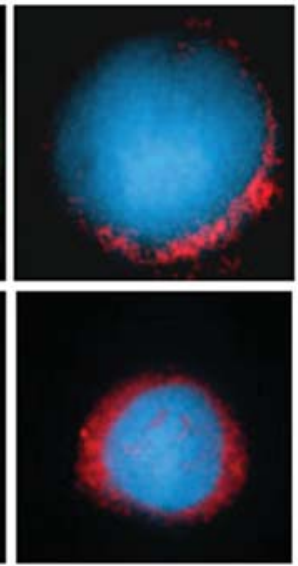
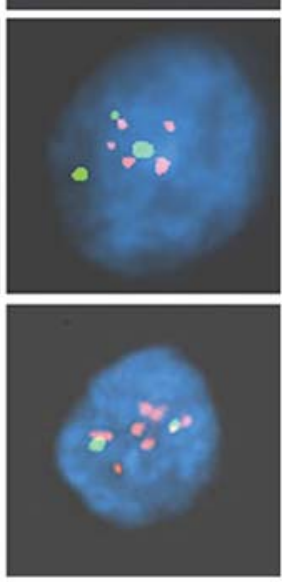

IF

$\frac{\text { HER2 }}{\text { CEP17 copy no. }}$

$0 / 1+$

$2 / 2$

25.74

$2+$

$5 / 3$

73.57

$3+$

$8 / 2$

Figure 3. HER2 status by confocal microscopy assay and FISH evaluation of CTCs from patients with primary breast cancer. Representative HER2 IF staining intensity of a single cell of $1+$ (first row), 2+ (second row) and 3+ (third row) are shown. Horizontally, the photographs show the same cell stained with IF for CK in green and HER2 in red (left); (middle) HER2 (red) only; and evaluated by FISH (right). For FISH, probes for HER2 (spectrum orange) and CEP17 (spectrum green) were used for hybridization. HER2 IF staining intensity by confocal microscopy assay (mean gray value), IF score (0-3+) and HER2/CEP17 ratio for each cell are shown.

Table III. Her-2 expression category 3+ correlates with HER2/CEP17 ratio and Her-2 gene copies in CTCs.

\begin{tabular}{lccc}
\hline Subunits & Ratio & Copy numbers of HER2 & Copy numbers of CEP17 \\
\hline Number of CTCs & 131 & 131 & 131 \\
$\mathrm{R}^{\mathrm{a}}$ & 0.41 & 0.30 & -0.17 \\
$\mathrm{P}^{\mathrm{b}}$ & $<0.0001$ & $<0.0001$ & $>0.05$ \\
\hline
\end{tabular}

${ }^{\mathrm{a}} \mathrm{R}$, correlation coefficient by spearman correlation analysis and ${ }^{\mathrm{b}} \mathrm{P}-\mathrm{value}$ was determined by exact binomial t-test.

levels determined by confocal microscopy correlates with gene status very well in individual CTCs.

\section{Discussion}

The detection and characterization of CTCs/DTCs has the potential of elucidating the mechanisms associated with cancer progression, serving as a prognostic marker, or monitoring the genetic changes in the heterogeneous tumors in a multitude of metastatic sites. Currently there is no substitute for obtaining tumor cells shed from tumor tissue that have been shown to reflect the existing tumor heterogeneity at a particular point in time. A variety of methodologies, including RT-PCR, flow cytometry, IHC, IF and FISH, have been used to further characterize CTCs for detection of tumor markers as cancer progresses (10-13,20-22). Evaluation of tumor markers (e.g. HER2) by IF staining has unique advantage: simultaneous detection of up to 5-7 different tumor markers at the same tumor cell by choosing the appropriate fluorochromes.
However, present assay is relatively crude by subjectively dividing protein expressing levels into 3 categories based on judgment of the examiner. This study was directed to quantitate protein expression level of tumor markers on CTCs by confocal microscopy assay. We have developed and validated the confocal microscopy assay for quantifying HER2 expression of individual CTCs in a simple and convenient approach. CTCs with HER2 expression 3+ determined by confocal microscopy assay, which are regarded as HER2positive in this study, showed a good concordance with gene amplification by FISH analysis in all patients. By using subsets of 10 consecutive cells (bins), we concluded that Her2 expression 3+ in CTCs predicts HER2 overexpression in tumor with high probability. So, at least 10 CTCs in each patient need to be counted for determination of the HER2 status of patients.

Heterogeneity of HER2 gene status and expression levels was observed among the CTCs from single patients with either HER2+ or HER2- primary tumor (Table II). HER2+ CTCs were found in all 5 patients with HER2- primary tumor. The 
spread of cancer metastases may occur via the blood or the lymphatics. It is conceivable that these HER2+ CTCs have advantages for growth and spread and may overtake the HER2- tumor cells. Therefore, their predominance of distant metastases could lead to a change of the HER2 status within the metastases at later stage. Further comprehensive characterization of CTCs by gene array, proteomics and comparative genomic hybridization $(\mathrm{CGH})$ would allow examination of the whole gene or protein profile in individual tumor cells $(21,23)$, which may provide new insights into mechanisms of metastasis and more 'tailored' targeted therapy (24).

In conclusion, this study has significant implications in quantification of HER2 expression in individual CTCs or DTCs by confocal microscopy assay. We found that there was a significant positive correlation between HER2 overexpression and gene amplification in individual CTCs, which provided validation of confocal microscopy assay for HER2 expression in CTCs. These results may provide interpretive guidelines for HER2 status assay in CTCs.

\section{Acknowledgements}

We thank Dr Chunli Li for technical help and advice in microscopy; Ms. Fulian Liao for cells culture. This study was supported by a grant from Major State Basic Research Development Program of China (973 Program) (No. 2007CB512802) and a grant from The International Science and Technology Cooperation Project (2007DFC30240).

\section{References}

1. Fehm T, Solomayer EF, Meng SD, Tucker T, Lane N, Wang J and Gebauer G: Methods for isolating circulating epithelial cells and criteria for their classification as carcinoma cells. Cytotherapy 7: 171-185, 2005.

2. Alix-Panabières $\mathrm{C}$, Riethdorf $\mathrm{S}$ and Pantel $\mathrm{K}$ : Circulating tumor cells and bone marrow micrometastasis: Clin Cancer Res 14: 5013-5021, 2008.

3. Panteleakou Z, Lembessis P, Sourla A, Pissimissis N, Polyzos A, Deliveliotis $\mathrm{C}$ and Koutsilieris M: Detection of circulating tumor cells in prostate cancer patients: methodological pitfalls and clinical relevance. Mol Med 15: 101-114, 2009.

4. Cristofanilli M, Budd GT, Ellis MJ, Stopeck A, Matera J, Miller MC, Reuben JM, Doyle GV, Allard WJ, Terstappen LW and Hayes DF: Circulating tumor cells, disease progression, and survival in metastatic breast cancer. N Engl J Med 351: 781-791, 2004.

5. Xenidis N, Perraki M, Kafousi M, Apostolaki S, Bolonaki I, Stathopoulou A, Kalbakis K, Androulakis N, Kouroussis C, Pallis T, Christophylakis C, Argyraki K, et al: Predictive and prognostic value of peripheral blood cytokeratin-19 mRNApositive cells detected by real-time polymerase chain reaction in node-negative breast cancer patients. J Clin Oncol 24: 3756-3762, 2006.

6. Scher HI, Jia X, de-Bono JS, Fleisher M, Pienta KJ, Raghavan D and Heller G: Circulating tumour cells as prognostic markers in progressive, castration-resistant prostate cancer: a reanalysis of IMMC38 trial data. Lancet Oncol 10: 233-239, 2009.

7. Meng SD, Tripathy D, Frenkel EP, Shete S, Naftalis EZ, Huth JF, Beitsch PD, Leitch M, Hoover S, Euhus D, Haley B, Morrison L, et al: Circulating tumor cells in patients with breast cancer dormancy. Clin Cancer Res 10: 8152-8162, 2004.

8. Wülfing P, Borchard J, Buerger H, Heidl S, Zänker KS, Kiesel L and Brandt B: HER2-positive circulating tumor cells indicate poor clinical outcome in stage I to III breast cancer patients. Clin Cancer Res 12: 1715-1720, 2006.

9. Attard G, Swennenhuis JF, Olmos D, Reid AH, Vickers E, A'Hern R, Levink R, Coumans F, Moreira J, Riisnaes R, Oommen NB, Hawche G, et al: Characterization of ERG, AR and PTEN gene status in circulating tumor cells from patients with castration-resistant prostate cancer. Cancer Res 69: 2912-2918, 2009.

10. Fehm T, Krawczyk N, Solomayer EF, Becker-Pergola G, Dürr-Störzer S, Neubauer H, Seeger H, Staebler A, Wallwiener D and Becker S: ERalpha-status of disseminated tumour cells in bone marrow of primary breast cancer patients. Breast Cancer Res 10: R76, 2008.

11. Meng SD, Tripathy D, Shete S, Ashfaq R, Haley B, Perkins S, Beitsch P, Khan A, Euhus D, Osborne C, Frenkel E, Hoover S, et al: HER-2 gene amplification can be acquired as breast cancer progresses. Proc Natl Acad Sci USA 101: 9393-9398, 2004.

12. Meng SD, Tripathy D, Shete S, Ashfaq R, Saboorian H, Haley B, Frenkel E, Euhus D, Leitch M, Osborne C, Clifford E, Perkins S, et al: UPAR and HER-2 gene status in individual breast cancer cells from blood and tissues. Proc Natl Acad Sci USA 103: 17361-17365, 2006.

13. Balic M, Lin H, Young L, Hawes D, Giuliano A, McNamara G, Datar RH and Cote RJ: Most early disseminated cancer cells detected in bone marrow of breast cancer patients have a putative breast cancer stem cell phenotype. Clin Cancer Res 12: 5615-5621, 2006.

14. Fehm T, Becker S, Duerr-Stoerzer S, Sotlar K, Mueller V, Wallwiener D, Lane N, Solomayer E and Uhr J: Determination of HER2 status using both serum HER2 levels and circulating tumor cells in patients with recurrent breast cancer whose primary tumor was HER2 negative or of unknown HER2 status. Breast Cancer Res 9: R74, 2007.

15. Chen C, Peng J, Xia HS, Yang GF, Wu QS, Chen LD, Zeng LB, Zhang ZL, Pang DW and Li Y: Quantum dots-based immunofluorescence technology for the quantitative determination of HER2 expression in breast cancer. Biomaterials 30: 2912-2918, 2009.

16. Giltnane JM, Molinaro A, Cheng H, Robinson A, Turbin D, Gelmon K, Huntsman D and Rimm DL: Comparison of quantitative immunofluorescence with conventional methods for HER2/neu testing with respect to response to trastuzumab therapy in metastatic breast cancer. Arch Pathol Lab Med 132: 1635-1647, 2008.

17. Steffensen KD, Waldstrøm M, Andersen RF, Olsen DA, Jeppesen U, Knudsen HJ, Brandslund I and Jakobsen A: Protein levels and gene expressions of the epidermal growth factor receptors, HER 1, HER2, HER 3 and HER4 in benign and malignant ovarian tumors. Int J Oncol 33: 195-204, 2008.

18. Tan BK, Tan LK, Yu K, Tan PH, Lee M, Sii LH, Wong CY, Ho GH, Yeo AW, Chow PK, Koong HN, Yong WS, et al: Clinical validation of a customized multiple signature microarray for breast cancer. Clin Cancer Res 14: 461-469, 2008.

19. Choudhury A, Charo J, Parapuram SK, Hunt RC, Hunt DM, Seliger B and Kiessling R: Small interfering RNA (siRNA) inhibits the expression of the HER2/neu gene, upregulates HLA class I and induces apoptosis of Her2/neu positive tumor cell lines. Int J Cancer 108: 71-77, 2004.

20. Pfitzenmaier J, Ellis WJ, Hawley S, Arfman EW, Klein JR, Lange PH and Vessella RL: The detection and isolation of viable prostate-specific antigen positive epithelial cells by enrichment: a comparison to standard prostate-specific antigen reverse transcriptase polymerase chain reaction and its clinical relevance in prostate cancer. Urol Oncol 72: 214-220, 2005.

21. Pinzani P, Salvadori B, Simi L, Bianchi S, Distante V, Cataliotti L, Pazzagli $\mathrm{M}$ and Orlando $\mathrm{C}$ : Isolation by size of epithelial tumor cells in peripheral blood of patients with breast cancer: correlation with real-time reverse transcriptase-polymerase chain reaction results and feasibility of molecular analysis by laser microdissection. Hum Pathol 37: 711-718, 2006.

22. Mocellin S, Keilholz U, Rossi CR and Nitti D: Circulating tumor cells: the 'leukemic phase' of solid cancers. Trends Mol Med 12: 130-139, 2006.

23. Fuhrmann C, Schmidt-Kittler O, Stoecklein NH, Petat-Dutter K, Vay C, Bockler K, Reinhardt R, Ragg T and Klein CA: Highresolution array comparative genomic hybridization of single micrometastatic tumor cells. Nucleic Acids Res 36: E39, 2008.

24. Cristofanilli M and Mendelsohn J: Circulating tumor cells in breast cancer: advanced tools for 'tailored' therapy. Proc Natl Acad Sci USA 103: 17073-17074, 2006. 